\title{
Assessment of Epstein-Barr Virus in Patients with Squamous Cell Carcinoma of the Larynx by Real-Time Polymerase Chain Reaction
}

\author{
Masoumeh Nouri', Mohammad Hasan Larizadeh", Hamid Reza Mollaei², Aliasghar Arabi Mianroodi, \\ Maryam Bahador', Sara Shamsi
}

\author{
'Department of Radiation Oncology, Afzalipour Hospital, Kerman University of Medical Sciences, Kerman, Iran. \\ 2Department of Medical Microbiology, Kerman University of Medical Sciences, Kerman, Iran. \\ 3Department of Otorhinolaryngology Head and Neck Surgery, Shafa Hospital, Kerman University of Medical Sciences, Kerman, Iran. \\ *Correspondence to: Mohammad Hasan Larizadeh (E-mail: mohammadhasanlarizadeh@yahoo.com) \\ (Submitted: 01 September 2021 - Revised version received:22 September 2021 - Accepted: 12 October 2021 - Published online: 26 December 2021)
}

\begin{abstract}
Objectives: This study was conducted to investigate the presence of Epstein-Barr virus (EBV) as a risk factor in laryngeal squamous cell carcinoma (SCC) and its effects on the pathological and clinical features of this disease.

Methods: This cross-sectional study was conducted on 55 patients with histologically confirmed laryngeal SCC in the pathology department of Shafa and Afzalipour hospital, Kerman, Iran, referred to the radiation oncology department between January 2018 and May 2019 (study group). Thirty-five patients who underwent surgery for benign laryngeal lesions such as polyps, nodules, cysts, or granulomas were considered as the control group. Biopsy specimens of all subjects were examined for the presence of EBV DNA by Real-Time Polymerase Chain Reaction (RT-PCR). Demographic and clinicopathological characteristics of all patients were recorded and patients with laryngeal SCC were followed up regarding relapse. The data were analyzed using SPSS-17 software and descriptive and analytical statistics were done.

Results: The incidence of EBV infection in patients with laryngeal SCC was 32.7\% (95\% Cl: 5/45 - 21/8) and this amount was 2.9\% (95\% $\mathrm{Cl}: 0$ - 8.6) in the control group. Based on multivariate logistic regression model, age (OR:1.05, 95\% Cl: 1.00 - 1.10, P-value: 0.04), EBV (OR: 9.76, 95\% Cl: 1.07 - 88.59, P-value: 0.04), smoking (OR: 6.82, 95\% Cl: 1.69 - 27.53, P-value: 0.007) and opium consumption (OR: 6.46, 95\% Cl: 1.36 - 30.66, P-value: 0.01) were determined as predictors of laryngeal SCC. In the patients' group, the presence of EBV was associated with a higher lymph node stage, which was statistically significant but there was no significant relationship in terms of age, sex, tumor location and $T$ stage and relapse.

Discussion \& Conclusion: This study showed an association between EBV as a risk factor and laryngeal SCC.

Keywords: Epstein-barr virus, laryngeal squamous cell carcinoma, real-time polymerase chain reaction
\end{abstract}

\section{Introduction}

Squamous cell carcinoma (SCC) of the larynx is a common malignancy that is associated with a high rate of disability and mortality. ${ }^{1}$ The role of many factors, especially tobacco and alcohol consumption, have been confirmed in the development of laryngeal SCC, but the rate of this malignancy is also increasing in people who do not smoke or drink alcohol. ${ }^{2}$ Recent studies have investigated the role of viruses in developing this type of cancer. ${ }^{3-5}$

Epstein-Barr virus (EBV) is a virus that can cause cancer and is transmitted orally and infects more than $95 \%$ of people in the first decade of life. ${ }^{1}$ Although the role of the virus in the pathogenesis of some head and neck cancers, such as nasopharyngeal cancer, is well known, there are limited studies available on the association of EBV with laryngeal SCC that have shown different results, and the role of EBV in the laryngeal SCC is still unclear. ${ }^{4,6-9}$

Although laryngeal cancer mainly affects the glottis in most parts of the world, studies in Iran and Mediterranean countries have reported that the tumor site is mainly in the supraglottis. ${ }^{10-12}$ On the other hand, it is estimated that the high prevalence of supraglottic cancers than glottis ones in some geographical areas is due to differences in the prevalence of the EBV virus in different locations. Despite the importance of laryngeal cancer, the result of previous studies on the role of EBV in this entity is controversial and has not yet been studied in Iran. ${ }^{6,713}$ In the present study, the incidence of EBV in specimens of benign and malignant lesions of the larynx was investigated by RT-PCR. Also, the effects of EBV on pathological and clinical features of the patients with laryngeal SCC were investigated.

\section{Materials and Methods}

In the present study, patients with histologically confirmed laryngeal SCC in the pathology department of Shafa and Afzalipour hospital, Kerman, Iran, referred to the radiation oncology department between January 2018 and May 2019, were considered as the study group.

Patients who underwent surgery for benign laryngeal lesions such as polyps, nodules, cysts, or granulomas were considered as the control group while individuals with a biopsy showing precancerous lesions such as leukoplakia or dysplasia were excluded.

Demographic information of all subjects, including age and sex, as well as a history of alcohol consumption, cigarette smoking and opium use, lesion location (glottis, supraglottis, and subglottis), grade (G1: well, differentiated, G2: moderately differentiated, G3: Poorly differentiated) and stage of the disease (T, N, M staging, AJCC 2017) were collected and entered in a form designed for registration.

Patients with laryngeal SCC were visited every 4 to 8 weeks for the first 2 years and then every 3 months. 
During follow-up visits, patients underwent history taking, physical and fiberoptic examination. If relapse was suspected, laryngeal biopsy would be taken.

All tissue samples (paraffin-embedded blocks) included in the study were examined for the detection of EBV DNA by RT-PCR.

The molecular tests of detecting EBV DNA by RT-PCR were performed based on the following steps:

1. Preparation of pathological samples in tissue processor device which contains formalin, ethanol, and xylol. molding samples by paraffin molds, and removing formalin from the tissue in several stages.

2. Virus DNA extraction using RIBO-Prep commercial kit, according to the manufacturer's instructions.

\section{The Quantitative and Qualitative Examination of the Extracted DNA}

The quantity and quality (amount of protein and polysaccharide contaminants) of the extracted DNA were evaluated by the absorption rate of the samples at 260 and $280 \mathrm{~nm}$ and the calculation of the adsorption ratios of $260 / 260 \mathrm{~nm}$ using the NanoDrop spectrophotometer. To detect the absence of fractures and the integrity of the DNA, the same amount of extracted DNA was electrophoresed on the $1.5 \%$ agarose gel containing ethidium bromide.

\section{Study of light absorption NanoDrop device}

At this stage, to measure the amount of DNA extracted, the amount of $2 \mu \mathrm{l}$ of the DNA sample was poured into a $0.2 \mathrm{ml}$ microtube, and after adding $98 \mu \mathrm{l}$ of distilled water to it, the absorbance of the solution was measured at a wavelength of $260 \mathrm{~nm}$. Finally, according to the DNA absorption coefficient at $260 \mathrm{~nm}$, and also, the dilution coefficient of 50, the amount of DNA was calculated.

4. Identification of samples for EBV contamination using Real-time PCR tests

Real-time PCR was used to detect the EBV virus. This method uses a primer and a probe specific for the BZLF5 virus gene region, which is responsible for the synthesis of viral DNA polymerase. Sequences of these areas are given below.

\section{Primer 1: CGGAAGCCCTCTGGACTTC Primer 2: CCCTGTTTATCCGATGGAATG Prob e FA M - T G TA C A C G C A C G A G A A A T G - CGCC-BHQ1}

After extracting the virus genome, $10 \mu \mathrm{l}$ of mastermix $2 \mathrm{x}$, $0.5 \mu \mathrm{l}$ of primer and probe with a final concentration of $10 \mathrm{nmol}$, $4.5 \mu \mathrm{l}$ of DEPC sterile water, and finally, $5 \mu \mathrm{l}$ of DNA and the extracted sample were added to $0.2 \mathrm{~mL}$ microtubes. After a quick spin, control samples with unknown samples were placed in Real-time PCR (Rotor-Gene 6000, Australia, and Corbett Research) and tested according to temperature profile $\left(95^{\circ} \mathrm{C}\right.$ for 10 minutes with 45 cycles $95^{\circ} \mathrm{C}$ for 15 seconds and $60^{\circ} \mathrm{C}$ for 40 seconds). Finally, positive samples in the green channel (FAM) were analyzed in terms of fluorescence at a temperature of $60^{\circ} \mathrm{C}$.

All collected data were plugged into the SPSS version 17 software. The mean and standard deviation indices were used to describe quantitative data and the percentage and frequency were used to describe qualitative data. The Chi-square test was also used to compare EBV positivity in the control and patient groups, to examine the positive relationship between EBV and other factors such as smoking and alcohol consumption, stage and degree of disease differentiation, and tumor location. Statistical significant level was considered at $P=0.05$.

\section{Results}

\section{Demographic Information of Subjects}

The present study was conducted on 55 patients with laryngeal cancer and 35 patients with benign laryngeal diseases. The mean age of subjects in this study was $58.04 \pm 11.55$ years old (age range: 31 to 88 ) for patients with laryngeal cancer and $46.89 \pm 14.63$ years old (age range: 9 to 71 ) for those with benign laryngeal diseases, respectively, and patients with cancer were older $(P=0.001)$. According to the findings, patients with laryngeal cancer were significantly different from those with benign laryngeal diseases in terms of sex, cigarette smoking, opium consumption, and EBV infection. The majority of cancer patients were male $(P=0.01)$ and more than three-quarter of them were cigarette smokers ( $80 \%$ versus $54.2 \% ; P=0.001)$ and opium consumers ( $87.3 \%$ versus $58.3 \%$, $P=0.004)$, and EBV infection was positive for more than onequarter of them $(32.7 \%$ versus $2.9 \%, P=0.001)$ in comparison to those with benign laryngeal diseases (Table 1).

\begin{tabular}{|c|c|c|c|c|}
\hline Variables & Level of variables & $\begin{array}{l}\text { Patients with laryngeal cancer } \\
\qquad(n=55)\end{array}$ & $\begin{array}{l}\text { Patients with benign laryngeal } \\
\text { diseases }(n=35)\end{array}$ & $P$-value \\
\hline Age (year) & & $58.04 \pm 11.55$ & $46.89 \pm 14.63$ & 0.001 \\
\hline \multirow[t]{2}{*}{ Sex } & Male & $51(92.7)$ & $26(74.3)$ & 0.01 \\
\hline & Female & $4(7.3)$ & $9(25.7)$ & \\
\hline \multirow[t]{2}{*}{ Cigarette smoking } & Negative & $11(20)$ & $11(45.8)$ & 0.001 \\
\hline & Positive & $44(80)$ & $13(54.2)^{*}$ & \\
\hline \multirow[t]{2}{*}{ Opium consumption } & Negative & $7(12.7)$ & $10(41.7)$ & 0.004 \\
\hline & Positive & $48(87.3)$ & $14(58.3)^{*}$ & \\
\hline \multirow[t]{2}{*}{ EBV infection } & Negative & $37(67.3)$ & $34(97.1)$ & 0.001 \\
\hline & Positive & $18(32.7)$ & $1(2.9)$ & \\
\hline
\end{tabular}

"The cigarette smoking and opium consumption of a patient with benign laryngeal diseases was unclear 


\begin{tabular}{|c|c|c|c|c|}
\hline Variables & Level of variables & $\begin{array}{c}\text { Cancer patients without } \\
\text { EBV }(n=37)\end{array}$ & $\begin{array}{l}\text { Cancer patients with EBV } \\
\qquad(n=18)\end{array}$ & $P$-value \\
\hline Age (year) & & $57.35 \pm 10.74$ & $59.44 \pm 13.26$ & $0.53^{\mathrm{a}}$ \\
\hline \multirow[t]{2}{*}{ Sex } & Male & $34(91.9)$ & $17(94.4)$ & $1^{b}$ \\
\hline & Female & $3(8.1)$ & $1(5.6)$ & \\
\hline \multirow[t]{2}{*}{ Cigarette smoking } & Negative & $7(18.9)$ & $4(22.2)$ & $1^{b}$ \\
\hline & Positive & $30(81.1)$ & $14(77.8)$ & \\
\hline \multirow[t]{2}{*}{ Opium consumption } & Negative & $4(10.8)$ & $3(16.7)$ & $0.67^{b}$ \\
\hline & Positive & $33(89.2)$ & $15(83.3)$ & \\
\hline \multirow[t]{3}{*}{ Histological grading } & G1 & $5(13.5)$ & $4(22.2)$ & $0.51^{\mathrm{b}}$ \\
\hline & G2 & $30(81.1)$ & $14(77.8)$ & \\
\hline & G3 & $2(5.4)$ & 0 & \\
\hline \multirow[t]{4}{*}{ T stage } & T1 & $4(10.8)$ & $1(5.6)$ & $0.62^{b}$ \\
\hline & $\mathrm{T} 2$ & $13(35.1)$ & $4(22.2)$ & \\
\hline & T3 & $18(48.6)$ & $11(61.1)$ & \\
\hline & T4 & $2(5.4)$ & $2(11.1)$ & \\
\hline \multirow[t]{4}{*}{ N stage } & NO & $32(86.5)$ & $8(44.4)$ & $0.002^{b}$ \\
\hline & N1 & $3(8.1)$ & $6(33.3)$ & \\
\hline & N2 & $1(2.7)$ & $4(22.2)$ & \\
\hline & N3 & $1(2.7)$ & 0 & \\
\hline \multirow[t]{3}{*}{ Location of cancer } & Subglottic & $1(2.7)$ & $1(5.6)$ & $0.40^{\mathrm{b}}$ \\
\hline & Glott & $12(32.4)$ & $3(16.7)$ & \\
\hline & Supraglottic & $24(64.9)$ & $14(77.8)$ & \\
\hline \multirow[t]{2}{*}{ Relapse } & Negative & $35(94.6)$ & $16(88.9)$ & $0.59^{b}$ \\
\hline & Positive & $2(5.4)$ & $2(11.1)$ & \\
\hline
\end{tabular}

astudent's t-test, bFisher's exact test.

\section{The Correlation of Demographic and Clinical Information with EBV Infection in Cancer Patients}

According to the findings, cancer patients with EBV infection were similar to other cancer patients based on demographic information such as age $(P=0.53)$, sex $(P=1)$, cigarette smoking $(P=1)$, and opium consumption $(P=0.67)$ (Table 2$)$. Among clinical information of cancer patients, only $\mathrm{N}$ staging was associated with EBV infection and cancer patients with EBV had higher $\mathrm{N}$ staging in comparison to other cancer patients without EBV infection $(P=0.004)$. The other clinical information was not statistically different between the two groups (Table 2).

The Mean follow-up time was $17.50 \pm 6.95$ months. Relapse occurred during the follow-up period in 4 patients with laryngeal SCC (7.27\%) with a mean time to recurrence of $11.50 \pm 7.59$ months. Two of these patients were EBV positive and the remaining was EBV negative. The mean time to recurrence in EBV positive group was $6.50 \pm 3.53$ months and in EBV negative group was $16.50 \pm 7.77$ months $(P$-value $=0.24)$.

\section{Discussion}

There are few studies on the relationship between EBV and SCC of the larynx and the results of previous studies on this issue are not conclusive. ${ }^{6,9,14,15}$ The present study was conducted to evaluate the prevalence of EBV infection in patients with laryngeal SCC and to compare it with patients with benign laryngeal diseases in Kerman. Findings showed that the prevalence of EBV infection in patients with laryngeal SCC was $32.7 \%$ (95\% CI: $21.8-5.45$ ). In patients with benign laryngeal diseases who were considered as controls, the prevalence of EBV infection was 2.9\% (95\% CI: 0.6-6). This finding is inconsistent with the study of Polz-Gruszka et al. (2015) in Poland, which tested serum EBV and LMP-1 antibodies in 64 patients with laryngeal cancer, 35 (54.7\%) of whom were EBV positive. ${ }^{16}$ The control group consisted of 40 cases, in 10 out of which, the virus genome was positive (25\%). The researchers concluded that the EBV virus is present in patients with pharyngeal and laryngeal cancer in Polish patients and that its wild form, in particular, is more closely associated with tumors. Lee et al. ${ }^{17}$ also reported EBV as an independent risk factor that causes laryngeal SCC. In contrast, in a study by Muderris et al. ${ }^{4}$ on 25 patients with laryngeal SCC and 17 patients with benign laryngeal lesions, fresh tissue samples were examined by PCR to detect EBV DNA. EBV DNA was positive in 40\% (10 of 25) of patients with laryngeal cancer and $47.1 \%$ (8 of 17) in the control group (benign lesions) with no significant difference $(P=$ 0.892). ${ }^{4}$ Therefore, in the present study, which includes a higher number of subjects than previous studies, a relationship was found between EBV and laryngeal SCC.

Old age is known as a risk factor for laryngeal SCC. ${ }^{18}$ The mean age of patients with laryngeal SCC in the present study 
was $58.04 \pm 11.55$ years old (age range: 31 to 88 years). The majority of patients $(n=53,96.36 \%)$ were over 40 years old and there was a significant relationship between increasing age and cancer incidence $(P=0.001)$. There was no statistically significant relationship between age and EBV infection in patients with laryngeal cancer $(P=0.53)$, which is consistent with the results of several previous studies. ${ }^{7,19}$

In this study, the majority of patients $(n=51,92.7 \%)$ were male and the rest were female $(n=4,7.3 \%)$. Based on the findings of this study, there was no relationship between the frequency of EBV infection and the gender of cancer patients $(P=1)$, which is consistent with the results of the study of Zhang et al. ${ }^{19}$

Cigarette smoking and alcohol consumption are known as risk factors of laryngeal SCC. ${ }^{20}$ In this study, none of the patients reported a history of alcohol consumption but more than three-quarters of cancer patients reported smoking (44, $80 \%)$ and there was a significant relationship between cigarette smoking and SCC of the larynx $(P=0.02)$. Opium consumption is also a risk factor for developing head and neck cancer. ${ }^{21}$ It was also found that more than $80 \%$ of cancer patients were opium users ( $n=48,87.3 \%)$, and there was a significant relationship between opium use and laryngeal SCC $(P=0.006)$ but there is no association between EBV infection and smoking $(P=1)$ or opium use $(P=0.67)$ in cancer patients. This finding is consistent with the result of the study of Muderris et al., who also found no association between alcohol consumption and smoking and EBV infection in cancer patients.

In cancer patients, the most common lesion site was the supraglottic region (38 cases, $69.1 \%$ ), followed by the glottis region (15 cases, $27.3 \%)$. In only two patients, a lesion was observed in the subglottic region (3.6\%). Findings from the study showed that there was no association between the lesion site of cancer and EBV infection $(P=0.40)$. This finding is consistent with the results of the study of VazquezGuillen et al., ${ }^{7}$ who found that EBV DNA in patients with laryngeal SCC and EBV was positive in $22.1 \%$ of glottic cancer, $16.7 \%$ of subglottic cancer, and $33.3 \%$ of supraglottic malignancy. There was no difference between the EBV DNA and the tumor location in their study. ${ }^{7}$ In contrast, Břicháček et al. ${ }^{22}$ reported an association between laryngeal supraglottic carcinoma and EBV infection, and also, found that EBV DNA was positive in 3 out of 5 patients with supraglottic laryngeal cancer. ${ }^{21}$

In the present study, more than one-third of cancer patients was in T2N0 stage $(n=22,40 \%)$, followed by T3N0T1-3N1 stage $(n=20,36.4 \%)$, stage T4N0 $(n=10,18.2 \%)$, T1-4N2-3 ( $n=10,18.2 \%)$, and T1N0 $(n=3,5.5 \%)$, respectively. EBV has no significant relationship with the $\mathrm{T}$ stage $(P=0.62)$ but was associated with a higher lymphatic stage $(P=0.002)$. Also, no relationship was found between pathological grade and virus burden $(P=0.51)$. In a study by $\mathrm{Al}$-Thawadi et al..$^{23}$ that examined the association of this virus with the histopathological and clinical features of head and neck cancers, no association was found between EBV infection and tumor grade or disease stage, ${ }^{22}$ which is consistent with the results of several other studies. ${ }^{4,8}$

The effect of EBV on the prognosis of laryngeal SCC has been controversial. ${ }^{17,24}$ In the present study, 4 patients relapsed, among whom two patients were EBV positive and the other ones were EBV negative. There was no significant relationship between EBV and relapse incidence $(P=0.59)$. So, further studies on the effect of EBV on prognosis and risk of disease relapse are recommended.

The effects of co-infection of EBV with other oncogene viruses were determined in different head and neck cancers. ${ }^{5,16}$ In the present study, only the EBV virus was assessed, so we plan to investigate the effect of co-infection of oncogene viruses on clinicopathologic characteristics and prognosis of this type of cancer.

\section{Conclusion}

The findings of the present study showed an association between EBV as a risk factor and laryngeal SCC. Although in this study, the presence of EBV in supraglottic cancers was higher than in other laryngeal sites, this relationship was not significant. Due to the small sample size in the group of cancer patients, further studies with larger sample sizes are recommended to investigate this relationship.

\section{References}

1. Singh SP, Eisenberg R, Hoffman G. An overview and comparative evaluation of head and neck cancer risk factors in India and Australia. International Journal of Otolaryngology and Head \& Neck Surgery. 2018;7(05):254.

2. Marur S, Forastiere AA, editors. Head and neck cancer: changing epidemiology, diagnosis, and treatment. Mayo Clinic Proceedings; 2008 Elsevier

3. Ahmadi N, Ahmadi N, Chan MV, Huo YR, Sritharan N, Chin R. Laryngeal squamous cell carcinoma survival in the context of human papillomavirus: a systematic review and meta-analysis. Cureus. 2018;10(2).

4. Muderris T, Rota S, Muderris T, Inal E, Fidan I. Does Epstein-Barr virus infection have an influence on the development of laryngeal carcinoma? Detection of EBV by real-time polymerase chain reaction in tumour tissues of patients with laryngeal carcinoma. Brazilian Journal of Otorhinolaryngology. 2013;79(4):418-23

5. Gupta I, Ghabreau L, Al-Thawadi H, Yasmeen A, Vranic S, Al Moustafa A-E, et al. Co-incidence of human papillomaviruses and epstein-barr virus is associated with high to intermediate tumor grade in human head and neck cancer in Syria. Frontiers in Oncology. 2020;10:1016

6. de Oliveira DE, Bacchi MM, Macarenco RS, Tagliarini JV, Cordeiro RC, Bacchi CE. Human papillomavirus and Epstein-Barr virus infection, p53 expression,

and cellular proliferation in laryngeal carcinoma. American Journal of Clinical Pathology. 2006;126(2):284-93.

7. Vazquez-Guillen JM, Palacios-Saucedo GC, Rivera-Morales LG, AlonzoMorado MV, Burciaga-Bernal SB, Montufar-Martinez M, et al. Infection and coinfection by human papillomavirus, Epstein-Barr virus and Merkel cell polyomavirus in patients with squamous cell carcinoma of the larynx: a retrospective study. Peer J. 2018;6:e5834

8. Kiaris H, Ergazaki M, Segas J, Spandidos D. Detection of Epstein-Barr virus genome in squamous cell carcinomas of the larynx. The International Journal of Biological Markers. 1995:10(4):211-5.

9. Mousa MJ. The frequency of epstein-barr virus infection as a pathogenic agent in laryngeal carcinoma of Iraqi patients demonstrated by LMP-1 expression. Journal of University of Babylon. 2016;24(3).

10. Saedi B, Razmpa E, Sadeghi M, Mojtahed M, Mojtahed A. The epidemiology of laryngeal cancer in a country on the esophageal cancer belt. Indian Journal of Otolaryngology and Head \& Neck Surgery. 2009:61(3):213-7.

11. Emadzadeh M, Shahidsales S, Bajgiran AM, Salehi M, Massoudi T, Nikfarjam Z, et al. Head and neck cancers in North-East Iran: a 25 year survey. Iranian Journal of Otorhinolaryngology. 2017;29(92):137. 
12. Larizadeh MH, Damghani MA, Shabani M. Epidemiological characteristics of head and neck cancers in southeast of Iran. Iranian Journal of Cancer Prevention. 2014;7(2):80.

13. Zykova T, Kit OI, Vladimirova LY, Ryadinskaya LA, Shevyakova EA, Bogomolova OA, et al. Impact of viral infection on effectiveness of antitumor treatment for laryngeal cancer. American Society of Clinical Oncology; 2018

14. Mulder FJ, Klufah F, Janssen FM, Farshadpour F, Willems SM, de Bree R, et al. Presence of human papillomavirus and Epstein-Barr virus, but absence of Merkel cell polyomavirus, in head and neck cancer of nonsmokers and non-drinkers. Frontiers in Oncology. 2021;10:3048.

15. Prabhu SR, Wilson DF. Evidence of Epstein-Barr virus association with head and neck cancers: a review. J Can Dent Assoc. 2016;82(g2):1488-2159.

16. Polz-Gruszka D, Stec A, Dworzański J, Polz-Dacewicz M. EBV, HSV, CMV and HPV in laryngeal and oropharyngeal carcinoma in Polish patients. Anticancer Research. 2015;35(3):1657-61.

17. Lee LA, Fang TJ, Li HY, Chuang HH, Kang CJ, Chang KP, et al. Effects of epstein-barr virus infection on the risk and prognosis of primary laryngeal squamous cell carcinoma: a hospital-based case-control study in Taiwan. Cancers. 2021;13(7):1741.

18. Halmos G, Bras L, Siesling S, van der Laan B, Langendijk J, van Dijk B. Age-specific incidence and treatment patterns of head and neck cancer in the Netherlands - a cohort study. Clinical Otolaryngology. 2018;43(1): 317-24.

19. Zhang $Y$, Chen $X$, Xia L, Can L, Dan L, Ruixia M, et al. Correlation of positive expressions of HPV and EBV with laryngeal carcinoma. The Journal of Practical Medicine. 2017;33(13):2117-22

20. Nocini R, Molteni G, Mattiuzzi C, Lippi G. Updates on larynx cancer epidemiology. Chinese Journal of Cancer Research. 2020;32(1):18.

21. Alizadeh H, Naghibzadeh-Tahami A, Khanjani N, Yazdi-Feyzabadi V, Eslami H, Borhaninejad V, et al. Opium use and head and neck cancers: a matched case-control study in Iran. Asian Pacific Journal of Cancer Prevention: APJCP. 2020;21(3):783

22. Břicháček B, Hirsch I, Šíbl O, Vilikusova E, Vonka V. Association of some supraglottic laryngeal carcinomas with EB virus. International Journal of Cancer. 1983;32(2):193-7.

23. Al-Thawadi H, Gupta I, Jabeen A, Skenderi F, Aboulkassim T, Yasmeen A, et al. Co-presence of human papillomaviruses and Epstein-Barr virus is linked with advanced tumor stage: a tissue microarray study in head and neck cancer patients. Cancer Cell International. 2020:20(1):1-13.

24. Vlachtsis K, Nikolaou A, Markou K, Fountzilas G, Daniilidis I. Clinical and molecular prognostic factors in operable laryngeal cancer. European Archives of Oto-Rhino-Laryngology and Head \& Neck. 2005;262(11): 890-8.

This work is licensed under a Creative Commons Attribution-NonCommercial 3.0 Unported License which allows users to read, copy, distribute and make derivative works for non-commercial purposes from the material, as long as the author of the original work is cited properly. 